\title{
Da tela da TV para as redes sociais digitais: o transbordamento do Jornal da Record no TikTok \author{
the overflow of Jornal da Record on TikTok
} \\ From the TV screen to digital social networks:
}

\author{
Valquíria Aparecida Passos Kneipp \\ Doutora em Ciência da Comunicação pela Escola de Comunicações e Artes da USP. Professora Associada da Universidade \\ Federal do Rio Grande do Norte. E-mail: valquiriakneipp@yahoo.com.br
}

\begin{abstract}
Resumo:
Diante do cenário de convergência e midiatização, telejornais reconfiguram o conteúdo exibido pela TV para as redes sociais digitais e plataformas. Com o objetivo de investigar este cenário contemporâneo dos telejornais e identificar novas práticas sociais no telejornalismo, esta pesquisa, tendo como objeto de estudo o Jornal da Record, busca responder como e por que o telejornal adotou o TikTok como parte da estratégia editorial. De acordo com o objeto empírico e o contexto do fenômeno analisado, este estudo exploratório se caracteriza como um estudo de caso. Com a análise foi possível identificar que a utilização do TikTok é uma estratégia de transmidiação para evitar a queda da audiência da TV aberta e para atrair o público jovem, que prefere as redes sociais digitais para obter informações.
\end{abstract}

\section{Palavras-chave:}

Convergência; Jornal da Record; Midiatização; Telejornalismo; TikTok; Transmídia.

\begin{abstract}
:
In the face of the convergence and mediatization scenario, TV newscasts reconfigure the content shown by TV to digital social networks and platforms. Looking for investigate this contemporary scenario of TV newscasts and to identify new social practices in telejournalism, this research, which uses Jornal da Record as its object of study, aims to understand how and why the television newscast adopted TikTok as part of its editorial strategy. According to the empirical object and context of the analysed phenomenon, this exploratory study is a case study. With the analysis, it was possible to identify that TikTok adoption is a transmediation strategy to avoid the drop im the open TV audience and to attract younger viewers who prefer digital social networks to get information.
\end{abstract}

\section{Keywords:}

Convergence; Jornal da Record; Mediatization; Telejournalism; TikTok; Transmedia. 


\section{As novas telas do telejornalismo}

No cenário contemporâneo de convergência (JENKINS, 2009) e midiatização (HJARVARD, 2012 e 2014), o Jornal da Record se reconfigura, transborda e amplia o conteúdo exibido pela TV para as redes social digitais e também outras plataformas, como uma forma de acompanhar a sua audiência, principalmente o público jovem, com mais conteúdo além do que é exibido tradicionalmente. Segundo um estudo da Kantar Ibope Media ${ }^{1}$, a mídia TV, de maneira geral, perdeu metade do público nos últimos 20 anos e a única exceção entre as emissoras de TV aberta brasileiras é a TV Record. Esses dados suscitam questionamentos sobre o destino dessa audiência. Muito provavelmente o cenário pós-digitalização abriu novas possibilidades de telas como celular, tabletes, redes sociais digitais, games e agora, com maior força, os serviços de streaming são os principais concorrentes da clássica televisão aberta. São novas telas que exibem conteúdo audiovisual e podem ser consideradas um tipo de televisão, mas que, ao contrário da TV aberta, exibem conteúdo ao vivo e sob demanda, contando também com um extenso banco de opções disponíveis para o usuário. Ou seja, o telespectador tem a possibilidade de escolher o que ver, como ver e quando ver - uma estratégia aparentemente mais democrática, mas em alguns casos com custos de assinaturas.

Nesse contexto, esta pesquisa objetivou investigar esse cenário transmidiático contemporâneo específico do telejornalismo, no Jornal da Record - denominado também como JR, para identificar as novas práticas sociais, diante da constante fuga do público para a internet. Feltrin $(2020)^{2}$ questiona para onde está indo este contingente de telespectadores que fugiu da frente da tela e responde: "A fuga tem ocorrido para justamente outras telas e mídias: para os celulares, tablets, redes sociais, a internet, os games e os agora temíveis e poderosos serviços de streaming." A escolha da Record se deve pelo fato de ela ter se tornado a única emissora brasileira que vem mantendo os índices de audiência e também por ser a primeira e única a utilizar a rede social TikTok (até o momento da pesquisa). Esses diferenciais tornaram a emissora

\footnotetext{
${ }^{1}$ Disponível: <https://www.uol.com.br/splash/noticias/ooops/2021/02/02/exclusivo-em-20-anosmetade-do-publico-ja-fugiu-da-tv-aberta.htm>.

${ }^{2}$ Disponível em: <https://www.uol.com.br/splash/noticias/ooops/2021/02/02/exclusivo-em-20-anosmetade-do-publico-ja-fugiu-da-tv-aberta.htm>.
}

INTERIN, v. 27, n. 1, jan./jun. 2022. ISSN: 1980-5276. 
uma fonte de observação e análise por configurar as diversas telas possíveis no telejornalismo atual, ou como a própria emissora se autodenomina: multiplataforma.

A hipótese inicial foi a de que, de maneira geral a emissora vem lançando mão de diversas estratégias para a consolidação do telejornalismo transmídia, por meio da ampla utilização de redes sociais digitais. Assim, com a criação de uma diretoria específica para planejamento transmídia, o TikTok surge como uma das ferramentas propulsoras da aproximação com o público jovem.

A pesquisa buscou responder como e porque o Jornal da Record adotou o TikTok como estratégia de propagação de conteúdo. De acordo com a Pesquisa Brasileira de Mídia (2016), a televisão de maneira geral é a mídia de maior audiência e cobertura no Brasil. Fora isso, boa parte da população tem os telejornais como única fonte de informação, reafirmando a credibilidade que o telejornalismo tem junto ao telespectador no país, como importante fonte de informação.

O instrumental metodológico que caracteriza essa investigação como um estudo de caso compreende a pesquisa bibliográfica, a observação virtual, as entrevistas com a equipe de produção do Jornal da Record, porque, de acordo com Yin (2001), para analisar um fenômeno contemporâneo da comunicação de massa, deve-se inseri-lo em um contexto da vida real. $\mathrm{O}$ estudo de caso como estratégia dessa pesquisa trabalha "com o planejamento, a análise e a exposição das ideias - e não apenas com o foco tradicional da coleta de dados ou do trabalho de campo" (YIN, 2001, p. 20). Durante a realização da pesquisa, em função da ocorrência da pandemia do novo coronavírus, todas as atividades presenciais, como observação da redação e entrevistas foram convertidas para o modo remoto. A observação realizada de forma virtual foi a do conteúdo do Jornal da Record exibido pela TV e disponibilizado pela internet, no período de 4 a 9 de maio de 2020, assim como foram feitos acompanhamento e observação das redes sociais digitais e das plataformas de informação. As entrevistas com os profissionais foram realizadas de forma remota pelo Google Meet. A prática da observação nesse estudo foi entendida inicialmente como uma ferramenta fundamental para relacionar teoria e prática, na medida que se pretendia realizá-la de forma presencial (devido à pandemia, não foi possível). De acordo com Peruzzo (2005), existem três de papeis para o pesquisador, sendo o primeiro onde ele participa de todas as atividades; no segundo, ele é autônomo; e o

INTERIN, v. 27, n. 1, jan./jun. 2022. ISSN: 1980-5276. 
terceiro, onde o pesquisado é encoberto ou revelado, "o grupo pode ter ou não conhecimento do que está sendo observado" (PERUZZO, 2005, p. 134). O ato de observar é fundamental para analisar e compreender as relações das práticas adotadas pelos profissionais do telejornalismo entre si e o meio em que atuam, e, ainda, a sua relação com os conceitos e teorias que fundamentam a pesquisa. Ela se diferencia e complementa as demais técnicas adotadas por proporcionar uma experiência imersiva do pesquisador em uma situação de observador, neste caso, não participante do processo. Foi adotada e readequada para o formato virtual e com foco apenas no conteúdo, por ser a única forma disponível naquele momento e por conseguir proporcionar o levantamento de dados por meio de categorias e viabilizar a análise empírica do material coletado.

Além disso, a entrevista em profundidade (Duarte, 2009) também foi uma técnica utilizada para complementar a observação dados coletados e a análise. "A entrevista em profundidade é um recurso metodológico que busca, com a base em teorias e pressupostos definidos pelo investigador, recolher respostas a partir da experiência subjetiva de uma fonte, selecionada por deter informações que se deseja conhecer" (DUARTE, 2005, p. 62).

\section{Convergência e midiatização no telejornalismo pós-digitalização}

A convergência midiática, de acordo com Jenkins (2009), está ligada ao processo de desenvolvimento tecnológico da televisão e demais mídias impulsionadas pela digitalização e pela conexão. Mas, de acordo com ele, trata-se de "um processo contínuo de interstícios entre diferentes sistemas de mídia, não uma relação fixa." (JENKINS, 2009, p. 377). Nesta pesquisa, existe uma identificação com essa proposição de Jenkins (2009) ao se verificar todas as possibilidades que o telejornal estudado tem lançado mão no seu instrumental transmidiático. É possível localizar uma situação na qual múltiplos sistemas de mídia coexistem em parceria e conexão, ocasionando um fenômeno de grandes dimensões e desdobramentos, ao qual o autor propõe quatro possibilidades de leitura: a convergência alternativa, corporativa, cultural e tecnológica. Na convergência alternativa, existe "fluxo informal e às vezes não autorizado de conteúdos de mídia quando se torna fácil aos consumidores arquivar,

INTERIN, v. 27, n. 1, jan./jun. 2022. ISSN: 1980-5276. 
comentar os conteúdos, apropriar-se deles e colocá-los de volta em circulação" (JENKINS, 2009, p. 377), como ocorre com todo material audiovisual que o telejornal analisado disponibiliza nas mais diversas plataformas e redes de divulgação e de informação. Na convergência corporativa, existe um controle por parte das empresas porque existe um "fluxo comercialmente direcionado de conteúdos de mídia" (JENKINS, 2009, p. 377), como ocorre com os conteúdos comerciais que vêm de forma impositiva junto a outros conteúdos de informação e entretenimento. A convergência cultural altera o padrão cultural da própria sociedade devido à influência da mídia com uma "mudança na lógica pela qual a cultura opera, com ênfase no fluxo de conteúdos pelos canais de mídia" (JENKINS, 2009, p. 377) ou, como denomina Hjarvard (2012 e 2014), configura-se como um processo de midiatização. $\mathrm{Na}$ convergência tecnológica, por sua vez, ocorre uma superposição midiática a partir da “combinação de funções dentro do mesmo aparelho tecnológico" (JENKINS, 2009, p. 377), o que possibilita ao usuário realizar diversas atividades e consumir vários formatos de mídia numa mesma plataforma.

Sobre o processo de midiatização da sociedade contemporânea, é importante registrar que, em busca de um conceito, Hjarvard (2012, p. 53) apresenta o fenômeno como "um processo de dupla face no qual a mídia se transformou em uma instituição semi-independente na sociedade à qual outras instituições têm que se adaptar”. Para formular uma teoria da midiatização, o autor questiona como a mídia altera tanto o funcionamento interno de outras entidades sociais quanto suas relações mútuas.

Depois de identificar os vários campos da sociedade contemporânea, nos quais é possível observar os efeitos da midiatização, Hjarvard (2012, p. 58) estabelece conexões e comparações com algumas teorias da comunicação, como a teoria da modernidade de Thompson, porque vê a midiatização como parte do desenvolvimento da sociedade moderna: "a invenção da imprensa em meados do século XV presenciou o nascimento de uma tecnologia que tornou possível a circulação de informação na sociedade de um modo sem precedentes". Com livros, jornais, revistas, entre outras possibilidades impressas, acelerou-se o processo de modernização. Depois com o rádio, a TV e a Internet, houve como consequências culturais o surgimento de grandes organizações em nível nacional e global, que potencializa a circulação de informação

INTERIN, v. 27, n. 1, jan./jun. 2022. ISSN: 1980-5276. 
e a convergência entre mídias. De acordo com o autor (2012), os meios alteram a comunicação e interação humanas, por meio de quatro processos que:

\begin{abstract}
Em primeiro lugar, eles estendem as possibilidades de comunicação humana tanto no tempo quanto no espaço; em segundo, substituem as atividades sociais que anteriormente ocorriam face a face. Por exemplo, para muitos, o banco via internet substituiu o encontro físico entre os bancos e seus clientes. Em terceiro lugar, os meios de comunicação incentivam uma fusão de atividades; a comunicação pessoal se combina com a comunicação mediada e os meios de comunicação se infiltram na vida cotidiana. Finalmente, os atores de diferentes setores têm que adaptar seu comportamento para acomodar as valorações, os formatos e as rotinas dos meios de comunicação (HJARVARD apud SCHUZ, 2004, p. 59).
\end{abstract}

Para o autor, a midiatização pode ser um metaprocesso em paridade com a individualização e a globalização, "como um processo contínuo em que os meios alteram as relações e o comportamento humanos e, assim, alteram a sociedade e a cultura" (HJARVARD, 2012, p. 57; KROTZ, 2007, p. 59). A partir dessas reflexões, pode-se investigar sobre a condição do telejornal frente ao processo de midiatização da sociedade que cada vez mais busca estratégias transmídia para acompanhar o espectador, usuário nas mais diversas estruturas midiáticas e das mais variadas formas, como acontece no caso da utilização da rede social digital TikTok pelo Jornal da Record.

As estratégias empregadas pelo $J R$ constroem uma narrativa transmídia $\mathrm{O}$ termo "narrativa transmídia" [transmedia storytelling] foi utilizado pela primeira vez por Marsha Kinder e Mary Celeste Kearney como uma prática promocional envolvendo merchandising, adaptações, sequências e franquias (EVANS, 2011). Para Jenkins (2009), que popularizou o termo, a narrativa transmídia designa a utilização de várias plataformas midiáticas que convergem para contar uma história, sendo que cada novo texto contribui de forma distinta para tal. Uma vez que um único texto não conseguiria abranger todo o conteúdo da narrativa ou atingir toda a audiência, um texto central oferece vários pontos de acesso ao enredo, pontos esses que são explorados em outras mídias tais como jogos digitais, histórias em quadrinhos, sites, vídeos online, blogs, redes sociais etc. No caso de narrativa transmídia ideal, não há redundância de informações, mas cada mídia oferece novos níveis de revelação, que se juntam para compor a narrativa completa da franquia. Outra proposição que Jenkins (2009) coloca

INTERIN, v. 27, n. 1, jan./jun. 2022. ISSN: 1980-5276. 
é que a transmídia se apoia em uma tríade formada por convergência dos meios de comunicação $^{3}$, pela cultura participativa ${ }^{4}$ e pela inteligência coletiva. ${ }^{5}$

Por fim, cabe ainda nesta etapa relacionar a proposta de Fechine (2013) para adoção e nomeação de ferramentas utilizadas para a construção de uma narrativa transmídia, compondo um arsenal com estratégias (de propagação e expansão) e conteúdos (reformatados ${ }^{6}$, informativos $^{7}$, de extensão textual ${ }^{8}$ e de extensão lúdica ${ }^{9}$ ) de transmidiação.

\section{Os bastidores do Jornal da Record no TikTok}

Antes de entrar propriamente na análise, é importante pontuar que a TV Record é a emissora em atividade mais antiga do país e está no ar desde 1953. O Jornal da Record, que é hoje o seu principal telejornal, ao longo dos anos passou por várias mudanças, apresentadores e denominações. Foi criado pela emissora nos anos 1970. Depois passou a ser chamado de Jornal da Noite. Nos anos 1980, voltou ao ar, com direção de jornalismo de Dante Matiusse e apresentação de Paulo Markun e Silvia Poppovic. Na sequência, foi apresentado por Carlos Nascimento. Depois, em 2002, o jornalista Paulo Henrique Amorin passou a apresentar um quadro no Jornal da Record segunda edição, chamado Conversa Afiada. O jornalista Boris Casoy apresentou o $J R$ entre 1997 e 2005. Em 2006, passou ser apresentado por Celso Freitas e Janine Borba (KNEIPP, 2008). Depois, Janine Borba foi substituída por Adriana Araújo. Em março de 2020, devido à pandemia do novo coronavírus, o apresentador Celso Freitas deixou a bancada do telejornal e passou a realizar outras atividades em home office. A partir daí, ficaram na apresentação Christina Lemos e Sérgio Aguiar. O $J R$ sempre foi tido

\footnotetext{
3 "Ocorre dentro dos cérebros dos consumidores individuais e em suas interações sociais com outros" (JENKINS, 2009, P. 30).

${ }^{4}$ A cultura participativa contrasta com a noção de passividade do público, que abandona o papel de simples consumidor de produtos de mídias e passa a participar, interagir e até mesmo produzir seu próprio conteúdo midiático.

${ }^{5}$ A expressão "inteligência coletiva", cunhada pelo teórico francês Pierre Lévy refere-se à estratégia de consumo encontrada para fazer frente ao grande fluxo de informações dos nossos dias: "por haver mais informações sobre determinado assunto do que alguém possa guardar na cabeça, há um incentivo extra para que conversemos entre nós sobre a mídia que consumimos" (JENKINS, 2009, p. 381).

${ }^{6}$ Antecipação, recuperação e remixagem.

${ }^{7}$ Contextuais e promocionais.

${ }^{8}$ Extensões narrativas e diegéticas.

${ }^{9}$ Extensões vivenciais e de marca.
}

INTERIN, v. 27, n. 1, jan./jun. 2022. ISSN: 1980-5276. 
como o principal telejornal da emissora e contou com recursos para modernização e crescimento da audiência. Em 2019, a TV Record lançou o Novo Jornal da Record uma proposta arrojada de telejornalismo multiplataforma.

A proposta da emissora em termos de tecnologia é interagir e informar os telespectadores durante as 24 horas do dia: por isso, criou uma diretoria de planejamento transmídia, que conta com uma equipe de 50 jornalistas. Além disso, outra equipe de jornalistas trabalha na produção específica do telejornal que é exibido pela TV aberta e é retransmitido simultaneamente pelas redes sociais digitais e pelo aplicativo PlayPlus. No site da emissora, o $J R$ se intitula "o primeiro multiplataforma do segmento" ${ }^{10}$, contando com cinco edições diárias, sendo uma delas exclusiva para a internet e outros conteúdos exclusivos para outras mídias. Para efeito de pesquisa, selecionou-se a edição das 19h45, que tem uma hora de duração.

Entre as estratégias utilizadas para transbordar o conteúdo do telejornal para além da transmissão, estão a Record News, o portal de notícias (r7.com) e o aplicativo PlayPlus ${ }^{11}$ para celular e também perfis nas redes sociais digitais Facebook - com 1.202.822 seguidores -, Instagram - com 459 mil seguidores e um link para a comunicação com a redação (conforme imagem 1 abaixo) -, um canal no YouTube com 2,52 milhões de inscritos e que transmite a edição das $19 \mathrm{~h} 45$ ao vivo simultaneamente à TV nas três redes sociais digitais - e Twitter - com 359, 8 mil seguidores . No TikTok, há 343 mil e 700 seguidores e 3 milhões de "curtidas".

A proposta multiplataforma vem promovendo o aumento do engajamento, de acordo com a revista Tela Viva, desde que passou a ter presença 24 horas, com boletins ao vivo na TV e na internet, além de conteúdos em novos formatos. O JR registrou crescimento de mais de 50\% no YouTube (média das impressões e inscritos no canal); aumento de $400 \%$ das interações no Facebook; e, no Instagram, crescimento das impressões e o alcance do perfil de mais de $200 \%$. As métricas se referem ao período de agosto de 2019 a janeiro de $2020^{12}$.

\footnotetext{
${ }^{10}$ Disponível em: <https://noticias.r7.com/jr-na-tv/conheca-o-jornal-da-record-primeiromultiplataforma-no-segmento-14082020>.

${ }^{11}$ Plataforma de streaming com assinatura paga.

${ }^{12}$ Disponível em: <https://telaviva.com.br/12/02/2020/jornal-da-record-comeca-a-distribuir-conteudono-tiktok/>.
}

INTERIN, v. 27, n. 1, jan./jun. 2022. ISSN: 1980-5276. 
Imagem 1 - Link da Bio do Instagram

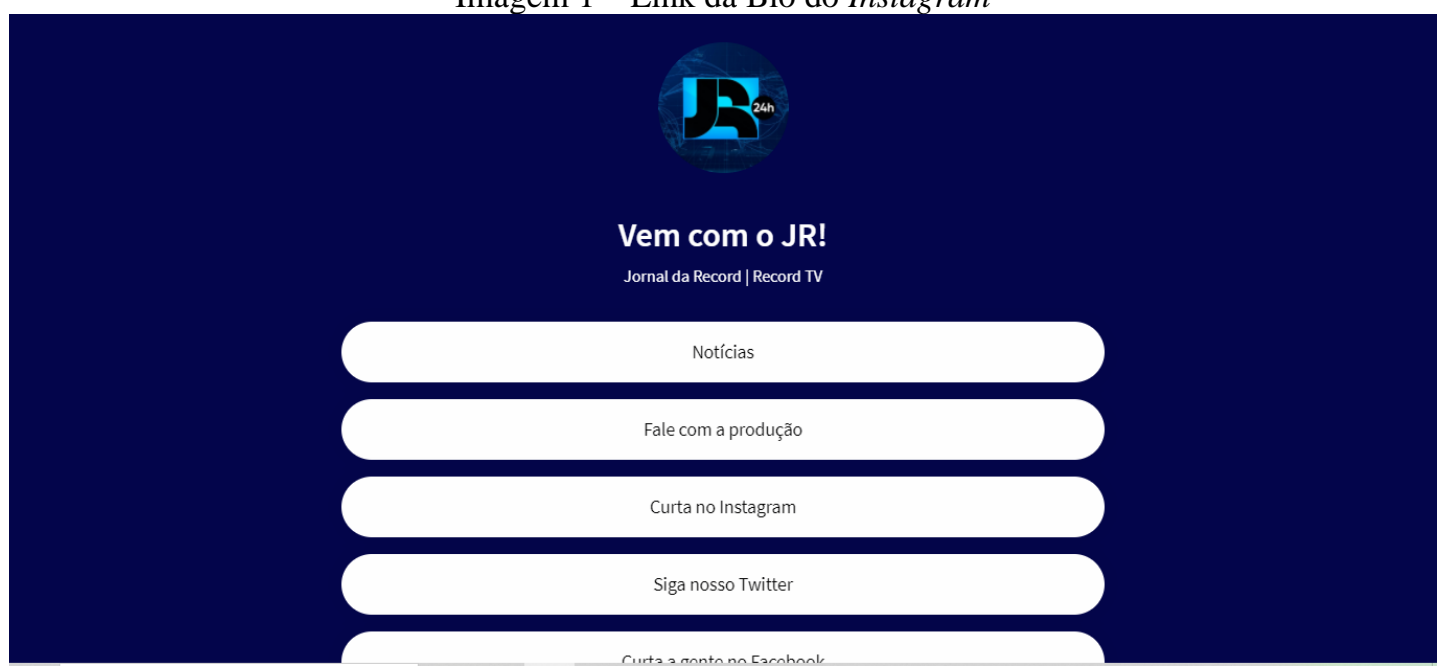

Fonte: <https://linklist.bio/jornaldarecord>.

O TikTok do JR (conforme Imagem 2) é a novidade em termos de telejornalismo. Trata-se de uma rede social digital mundial de origem chinesa. Até 2017 se denominava Douyyin e só era utilizada na China. Para disputar o mercado mundial, a empresa criadora ByteDance melhorou o seu desempenho, mudou o nome e comprou o aplicativo musical Musical.ly. Com um aplicativo mais completo, o TikTok passou a ser uma rede social destinada a vídeos curtos, na qual o usuário pode criar seu próprio conteúdo. Existem várias possibilidades, como clipes de dublagem, danças, vídeos de humor, entre outras. Também estão disponíveis diversos filtros e ajustes de velocidade, sendo isso muito difundido entre o público jovem, devido ao caráter de humor e entretenimento. Como a maioria das redes sociais digitais, no TikTok o usuário compartilha seus vídeos e pode seguir outros usuários, bem como dispor de uma série de vídeos sugeridos por meio de uma seleção, de acordo com o perfil de cada um. A rede social conta com os recursos de curtir, comentar e compartilhar. De acordo com consultoria Sensor Tower, no primeiro semestre de 2019, o TikTok possuía 500 milhões de usuários pelo mundo ${ }^{13}$.

${ }^{13}$ Disponível em: 〈https://segredosdomundo.r7.com/tik-tok/>.

INTERIN, v. 27, n. 1, jan./jun. 2022. ISSN: 1980-5276. 
Imagem $2-T i k T o k$ do $J R$
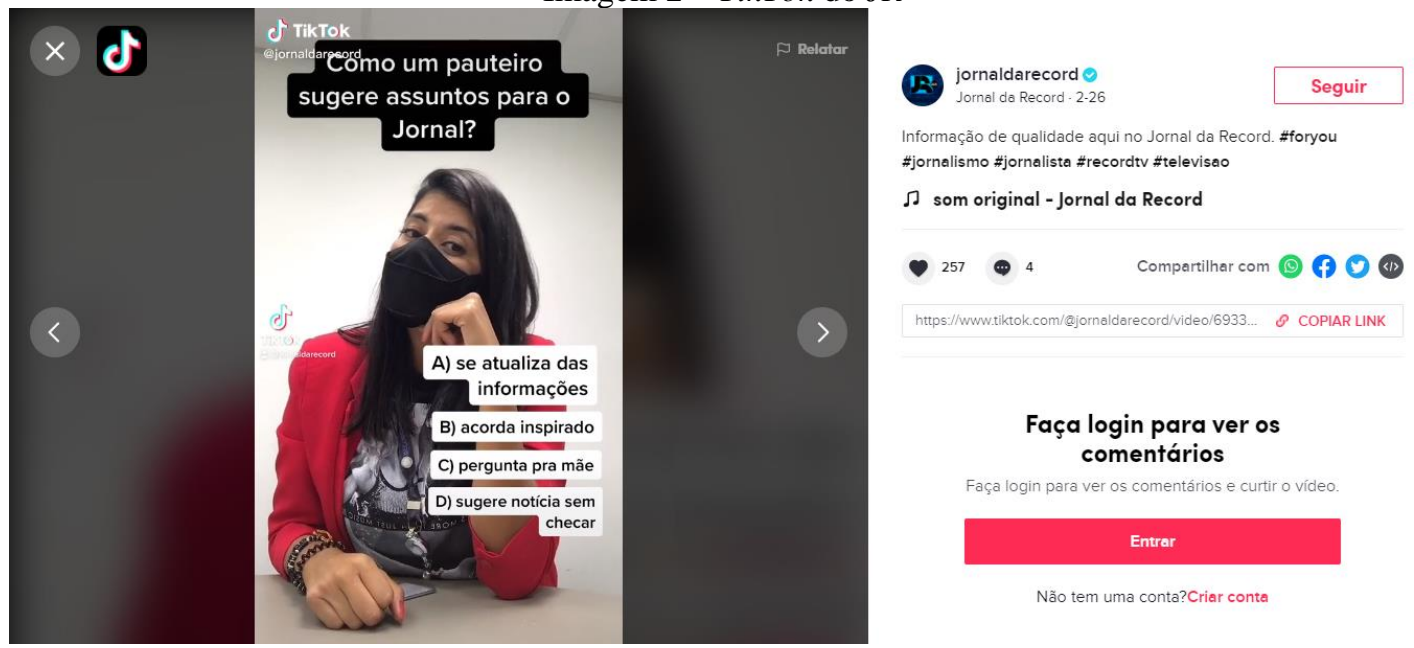

Fonte: www.tiktok.com/@jornaldarecord ${ }^{14}$

Sobre o uso do TikTok pelo $J R$, a proposta multiplataforma do telejornal é composta por estratégias e conteúdos transmídia, conforme o quadro 1 abaixo, que utiliza cinco redes sociais digitais, dois sites de informação e um aplicativo, no qual os mais diversos conteúdos são distribuídos 24 horas por dia. No caso específico do TikTok, segundo a revista Telaviva, o objetivo é "amplificar ainda mais sua audiência multiplataforma, visando a impactar especialmente o público jovem"15. No recorte tomado como exemplo acima (Imagem 2), de um vídeo postado no TikTok do JR, é possível observar no seu conteúdo que, de forma descontraída, uma pauteira da equipe mostra um pouco da sua rotina por meio de uma enquete. Ela questiona "como um pauteiro sugere assuntos para o jornal?"16 e algumas alternativas são apresentadas como resposta: “A) se atualiza das informações; B) acorda inspirado; C) pergunta pra mãe; D) sugere notícia sem checar" ${ }^{17}$, seguindo a tendência da rede social e com uma trilha sonora de suspense e performance da pauteira no vídeo. Quando é apontada a resposta correta, a trilha sinaliza e as alternativas são coloridas com as cores verde (indicando a resposta correta) e vermelho (indicando as respostas incorretas). Assim,

\footnotetext{
${ }^{14}$ Disponível em: <https://www.tiktok.com/@jornaldarecord/video/6933697420454907142? is_copy_url=1\&is_from_webapp=v1>.

${ }^{15}$ Disponível em: <https://telaviva.com.br/12/02/2020/jornal-da-record-comeca-a-distribuir-conteudono-tiktok/>.

${ }^{16}$ Disponível em: <https://www.tiktok.com/@jornaldarecord/video/6933697420454907142? is_copy_url=1\&is_from_webapp=v1>.

${ }^{17}$ Disponível em: <https://www.tiktok.com/@jornaldarecord/video/6933697420454907142? is_copy_url=1\&is_from_webapp=v1>.
}

INTERIN, v. 27, n. 1, jan./jun. 2022. ISSN: 1980-5276. 
de forma descontraída, revela-se um pouco das atividades desempenhadas por um profissional da equipe do telejornal, o pauteiro. Logo, confirma-se a hipótese inicial desta pesquisa de aproximação com o público jovem, por meio de conteúdos e curiosidades sobre o telejornal. De acordo com a editora chefe do $J R$, Patrícia Rodrigues (2020), "não sei se a gente pode chamar de diálogo ainda; o que eu acho que a gente consegue é fidelizar a marca e isso é bacana".

As estratégias e conteúdo transmídia adotados pelo $J R$ se apresentam nas duas categorias propostas por Fechine (2013): propagação e expansão, com conteúdo reformatado, informativo, de extensão textual e lúdica. As estratégias de propagação com conteúdos reformatados definidas pela autora são aquelas que "não oferecem informações novas, mas sim variações dos conteúdos produzidos para exibição na programação da TV” (FECHINE, 2013 p. 37) e estão disponíveis em três subcategorias: antecipação, recuperação e remixagem. Elas podem ser identificadas nas postagens diárias de todo o conteúdo do telejornal nas redes sociais Facebook, Instagram, YouTube e Twitter ao vivo durante a exibição pela TV e também por meio de postagens que variam de acordo com cada rede, sendo que no YouTube é disponibilizada a versão completa do telejornal (recuperação) e nas demais redes as matérias são disponibilizadas de forma individual (remixagem). Já no site de informação R7, é disponibilizado o conteúdo do telejornal por meio de podcast (reformatado).

As estratégias de propagação com conteúdos informativos são aquelas que “oferecem ao destinatário-consumidor informações associadas ou correlacionadas ao texto de referência" (FECHINE, 2013, p. 41), que nesse caso é o telejornal. As subcategorias contextuais e promocionais estão presentes nos dois sites de informação R7 e Record News por meio da disponibilização de informações complementares ao telejornal, proposta de exibição de notícias 24 horas por dia e também entrevistas exclusivas diárias. Vale destacar que no site Record News existe uma proposta de inclusão para cegos, na medida em que todo o conteúdo possui audiodescrição mecânica, numa estratégia de inclusão.

$\mathrm{Na}$ categoria estratégias de expansão, a categoria conteúdos de extensão textual, de acordo com Fechine (2013, p. 44) "são responsáveis por desdobramentos narrativos. Como o nome sugere, estendem o texto de referência". Neste estudo, é 
possível identificar as subcategorias "extensões narrativas" e "extensões diegéticas". As extensões narrativas são definidas por Jenkins (2009) como transmedia storytelling. No caso do $J R$, as extensões narrativas são configuradas por meio dos dois sites de informações (R7 e Record News) e redes sociais digitais, que disponibilizam uma live exclusiva todas as segundas-feiras com Adriana Araújo discutindo a Série JR.

A categoria conteúdos de extensão lúdica é, de acordo com Fechine (2013), aquela que convida o consumidor de mídia a brincar e participar. As duas subcategorias extensões vivenciais e extensões de marca podem ser identificadas na rede social digital TikTok. A primeira, na medida em que se desenvolvem através dela campanhas e informação de forma divertida relacionada com o universo do telejornal, por meio de vídeos engraçados mostrando os bastidores da redação; e a segunda, na medida que estes conteúdos colaboram para reforçar a marca do telejornal e chamam a atenção do público jovem.

Quadro 1 - Estratégias e conteúdos do Jornal da Record

\begin{tabular}{|c|c|c|c|}
\hline Denominação & Endereço & Tipo & Subcategoria \\
\hline Record News & $\begin{array}{c}\text { https://noticias.r7.com/record- } \\
\text { news }\end{array}$ & $\begin{array}{c}\text { Site de } \\
\text { informação }\end{array}$ & Extensão textual \\
\hline R7.com & https://www.r7.com/ & $\begin{array}{c}\text { Site de } \\
\text { informação }\end{array}$ & $\begin{array}{c}\text { Recuperação } \\
\text { Extensão textual }\end{array}$ \\
\hline PlayPlus & https://www.playplus.com/ & $\begin{array}{c}\text { Aplicativo para } \\
\text { celular }\end{array}$ & Conexão* \\
\hline Facebook & $\begin{array}{c}\text { https://www.facebook.com/Jorn } \\
\text { alDaRecord/?ref=page_internal }\end{array}$ & Rede Social & $\begin{array}{c}\text { Remixagem } \\
\text { Conexão* }\end{array}$ \\
\hline Instagram & $\begin{array}{c}\text { https://www.instagram.com/jorn } \\
\text { aldarecord/live/?hl=pt-br }\end{array}$ & Rede Social & $\begin{array}{c}\text { Remixagem } \\
\text { Conexão* }\end{array}$ \\
\hline YouTube & $\begin{array}{c}\text { https://www.youtube.com/chann } \\
\text { el/UCmpHPgeCBgvk_fDXZQK } \\
\text { snAA }\end{array}$ & Rede Social & $\begin{array}{c}\text { Remixagem } \\
\text { Conexão* }\end{array}$ \\
\hline TikTok & $\begin{array}{c}\text { https://www.tiktok.com/@jornal } \\
\text { darecord?source=h5_m\&is_cop } \\
\text { y_url=1\&is_from_webapp=v1 }\end{array}$ & Rede Social & $\begin{array}{c}\text { Extensões vivenciais } \\
\text { Extensões de marca }\end{array}$ \\
\hline Twitter & $\begin{array}{c}\text { https://twitter.com/jornaldarecor } \\
\text { d?ref_src=twsrc\%5Egoogle\%7 } \\
\text { Ctwcamp\%5Eserp\%7Ctwgr\%5 } \\
\text { Eauthor }\end{array}$ & Rede Social & $\begin{array}{c}\text { Recuperação } \\
\text { Conexão* }\end{array}$ \\
\hline
\end{tabular}

Fonte: elaborado com base nos dados de Fechine e proposta da autora

A utilização do aplicativo PlayPlus e as transmissões ao vivo pela redes sociais digitais não se encaixam em quaisquer das propostas conceituais de Fechine (2013) e sugerem uma ampliação das estratégias de transmidiação, com a proposta de criação dentro das estratégias de propagação de uma nova subcategoria na categoria conteúdos

INTERIN, v. 27, n. 1, jan./jun. 2022. ISSN: 1980-5276. 
informativos, que inicialmente pode ser denominada conexão (conforme marcada com asterisco no quadro 1), pois referem-se à possibilidade de conectar o conteúdo do telejornal por meio da tela do celular, computador ou outra nova tela para assistir ao telejornal de qualquer lugar mantendo-se em conexão com a notícias do telejornal, com o uso da internet e um aplicativo ou rede social digital.

Essas estratégias adotadas pelo $J R$ potencializam e amplificam o conteúdo do telejornal, corroborando assim para a efetivação de um telejornalismo transmídia e expandido em plataformas diferentes, cada qual com a sua linguagem própria, proporcionado pelo estágio de pós-digitalização em que a televisão brasileira se encontra e, ainda, abrindo o campo conceitual para se elaborar uma denominação para estes conteúdos que continuam circulando em diversas plataformas como uma espécie de pós-telejornal.

\section{Considerações Finais}

Ao investigar o cenário contemporâneo de convergência e midiatização, no $J R$ foi possível identificar um conjunto de novas práticas sociais adotadas pela emissora na forma de estratégias e conteúdos transmídia, conforme as propostas por Fechine (2013), com a utilização de múltiplas plataformas para se distribuir os conteúdos do telejornal e outros além dele. Por meio de oito diferentes plataformas de mídia, a emissora se propõe a distribuir informação 24 horas por dia, sendo necessário ampliar a proposta conceitual da autora para abarcar as novas possibilidades apresentadas, com a utilização de um aplicativo e também da transmissão do conteúdo do telejornal simultaneamente nas redes sociais digitais, com uma subcategoria denominada conexão. Desta forma, configura-se claramente o cenário de midiatização que "pode ser entendido como múltiplos entrecruzamentos entre tecnologias midiáticas, campos e atores sociais, meios de comunicação social tradicionais e sociedade (SGORLA, 2009, p. 62).

Foi possível considerar que a utilização específica do TikTok é uma proposta diferenciada das demais emissoras e tem como objetivo evitar a queda da audiência da TV aberta, que vem aumentando nos últimos 20 anos (conforme mostram as pesquisas) e também para atrair o público jovem, que prefere as redes sociais digitais para se

INTERIN, v. 27, n. 1, jan./jun. 2022. ISSN: 1980-5276. 
informar e tem maior disponibilidade para assistir conteúdos divertidos que mostram os bastidores do $J R$ e outras curiosidades da redação, de forma criativa e no tom descontraído da própria rede. Os dados apresentados mostram o crescimento do número de seguidores das redes sociais digitais do $J R$, mas ainda existem outras variáveis a se investigar no futuro, como o número de curtidas, compartilhamentos e mensagens, pois a emissora abre diversos canais para que o telespectador internauta possa se manifestar sobre os conteúdos disponibilizados e também para distribuir os mesmos.

A maneira com que o $J R$ se apropriou da ferramenta TikTok demonstra o esforço da emissora na busca de inovação, por meio do estudo e conhecimento das redes sociais digitais, com a criação de uma diretoria de planejamento transmídia para coordenar toda a produção e elaborar as melhores estratégias e plataformas a serem empregadas, para o engajamento e viralização dos conteúdos. Consolida-se assim, na prática, as propostas de Jenkins (2009) relativas à convergência como um processo contínuo, com diferentes sistemas em uma relação. O fenômeno também corrobora com a proposta de Jenkins (2009), na qual a transmídia - e por consequência as suas estratégias e conteúdos também - se apoia em uma tríade composta pela convergência dos meios, pela cultura participativa e pela inteligência coletiva.

A partir desta investigação também foi possível identificar nesse cenário de convergência de mídias e midiatização o surgimento de novas práticas sociais no telejornalismo, em que a diversidade de plataformas e de formatos de informações relacionados ao telejornal propõem um contexto pós-telejornal, com a possibilidade e encontrar informações durante as 24 horas do dia, independentemente do telejornal estar no ar, mas com as características e fidelidade dele.

\section{REFERÊNCIAS}

EVANS, Elizabeth. Transmedia television: audiences, new media and daily life. New York/London: Routledge, 2011.

FECHINE. Yvana. Social TV: contribuição para a delimitação do conceito. In:

Contracampo, v. 36, $\mathrm{n}^{\circ}$ 1, abril-julho, 2017. Disponível em:

<https://periodicos.uff.br/contracampo/article/view/17598>. Acesso em: 13 mai. 2019.

INTERIN, v. 27, n. 1, jan./jun. 2022. ISSN: 1980-5276. 
FELTRIN, Ricardo. Exclusivo: TV aberta perdeu quase metade do público em 20 anos. IN: UOL. Disponível em: <https://www.uol.com.br/splash/ noticias/ooops/2021/02/02/exclusivo-em-20-anos-metade-do-publico-ja-fugiu-da-tvaberta.htm>. Acesso em: 17 dez. 2021.

HJARVARD, Stig. Midiatização: conceituando a mudança cultural e social. In: Matrizes, v. 8, $\mathrm{n}^{\circ}$ 1, 2014. Disponível em:

<https://periodicos.uff.br/contracampo/article/view/17598>. Acesso em: 20 mai. 2019.

. Midiatização: teorizando a mídia como agente de mudança social e cultural. In: Matrizes, v. 5, $\mathrm{n}^{\mathrm{o}}$ 2, 2012. Disponível em: <https://www.revistas.usp.br/matrizes/article/download/38327/41182>. Acesso em: 25 mai. 2019.

JENKINS, Henry. Cultura da convergência. São Paulo: Aleph, 2009.

JORNAL DA RECORD. Informação de qualidade aqui no Jornal da Record. \#foryou \#jornalismo \#jornalista \#recordtv \#televisao. Disponível em: <https://www.tiktok.com/@jornaldarecord/video/6933697420454907142?is_copy_u rl=1\&is_from_webapp=v1>. Acesso em: 08 mar. 2021.

. Jornal da Record: Facebook. Disponível em: <https://www.facebook.com /JornalDaRecord/?ref=page_internal>. Acesso em: 08 mar. 2021.

.jornaldarecord: Instagram. Disponível em: <https://www.instagram.com /jornaldarecord/live/?hl=pt-br>. Acesso em: 08 mar. 2021.

. jornaldarecord: TikTok. Disponível em: <https://www.tiktok.com/

@ jornaldarecord?source=h5_m\&is_copy_url=1\&is_from_webapp=v1 $>$. Acesso em: 08 mar. 2021.

Jornal da Record: Twitter. Disponível em: <https://twitter.com/ jornaldarecord?ref_src=twsrc\%5Egoogle\%7Ctwcamp\%5Eserp\%7Ctwgr\%5Eauthor $>$ . Acesso em: 08 mar. 2021.

Jornal da Record: YouTube. Disponível em: <https://www.youtube.com/ channel/UCmpHPgeCBgvk_fDXZQKsnAA>. Acesso em: 08 mar. 2021.

Vem com o JR. Disponível em: <https://linklist.bio/jornaldarecord>. Acesso em: 08 de mar. 2021.

KNEIPP, Valquíria Aparecida Passos. Trajetória de formação do telejornalista brasileiro: as implicações do modelo americano. São Paulo: Escola de Comunicações e Artes/USP, 2008.

PERUZZO, Cicilia Maria Krohling. Observação participante e pesquisa-ação. In: DUARTE, Jorge, BARROS, Antonio. Métodos e técnicas de Pesquisa em Comunicação. São Paulo: Atlas, 2005.

PESQUISA Brasileira de Mídia. Disponível em: <http://pesquisademidia.gov.br/ \#/Geral/details-917>. Acesso em: 25 fev. 2019.

INTERIN, v. 27, n. 1, jan./jun. 2022. ISSN: 1980-5276. 
PLAYPLUS. Disponível em: <https://www.playplus.com/>. Acesso em: 08 mar. 2021.

R7. Disponível em: <https://www.r7.com/>. Acesso em: 08 mar. 2021.

Conheça o Jornal da Record, primeiro multiplataforma no segmento.

Disponível em: <https://noticias.r7.com/jr-na-tv/conheca-o-jornal-da-recordprimeiro-multiplataforma-no-segmento-14082020>. Acesso em: 08 mar. 2021.

Perfil do Jornal da Record no Tik Tok alcança 100 mil seguidores.

Disponível em: <https://noticias.r7.com/tecnologia-e-ciencia/perfil-do-jornal-darecord-no-tik-tok-alcanca-100-mil-seguidores-04072020>. Acesso em: 08 mar. 2021.

Tik Tok, o que é? Origem, como funciona, popularização e problemas.

Disponível em: <https://segredosdomundo.r7.com/tik-tok/>. Acesso em: 08 mar. 2021.

RECORD NEWS. Disponível em: 〈https://noticias.r7.com/record-news〉. Acesso em: 08 mar. 2021.

RODRIGUES, Patrícia. Entrevista realizada via Google Meet. Em: 17 de ago. 2020.

SGORLA, Fabiane. Discutindo o "Processo de Midiatização". Revista Mediação, v. $9, \mathrm{n}^{\circ} 9$ jan/jun 2009. Disponível em <

http://revista.fumec.br/index.php/mediacao/article/view/285>. Acesso em: $27 \mathrm{dez}$. 2021.

TELA VIVA. "Jornal da Record" começa a distribuir conteúdo no TikTok. Disponível em: <https://telaviva.com.br/12/02/2020/jornal-da-record-comeca-adistribuir-conteudo-no-tiktok/>. Acesso em: 08 mar. 2021.

UOL. Exclusivo: TV aberta perdeu quase metade do público em 20 anos. Disponível em: <https://www.uol.com.br/splash/noticias/ooops/2021/02/02/ exclusivo-em-20-anos-metade-do-publico-ja-fugiu-da-tv-aberta.htm>. Acesso em: 08 de março de 2021.

YIN, R. K. Estudo de caso: planejamento e métodos. $5^{\text {a }}$ ed. Porto Alegre: Bookman, 2005.

Recebido em: 25.07.2021

Aceito em: 16.12.2021

INTERIN, v. 27, n. 1, jan./jun. 2022. ISSN: 1980-5276. 